\title{
As poéticas de Abidoral Jamacaru enquanto registro de memória e representação do conhecimento
}

\author{
Ermeson Nathan Pereira Alves \\ Mestre; Universidade Federal da Paraíba, João Pessoa, PB, Brasil; \\ ermesonathan@hotmail.com \\ Anna Elizabeth Galvão Coutinho Correia \\ Doutora; Universidade Federal de Pernambuco, Recife, PE, Brasil; \\ aegcc3@gmail.com
}

\begin{abstract}
Resumo: Identifica as poesias de Abidoral Jamacaru como registro de memória da região ao sul do Estado do Ceará, Cariri. Contextualiza o poeta na década dos 'modernos marginais', ou seja, no movimento de contracultura nos anos 1970, no qual o artista começa a ter visibilidade e a se reconhecer enquanto sujeito que influenciou num dado período. Conceitua memória sob o viés da Ciência da Informação, dialogando com as concepções históricas da poesia. Quanto ao procedimento metodológico, a pesquisa se utiliza da Análise de Conteúdo, bem como a Análise Temática na operacionalização dos dados. Os mapas conceituais foram inseridos como tipos de representação do conhecimento, ampliando as formas de se visualizar a poesia de Abidoral Jamacaru. Conclui que a estética paisagística da Cidade de Crato e os movimentos de contracultura no Cariri influenciaram na composição dos escritos poéticos do autor, compondo a memória individual que dialoga com a memória local da região criando uma identidade em suas obras.
\end{abstract}

Palavras-chave: Abidoral Jamacaru. Registro de memória. Representação do conhecimento. Ciência da Informação.

\section{Introdução}

Este trabalho é resultante da Dissertação de Mestrado em Ciência da Informação, desenvolvida no âmbito da Universidade Federal de Pernambuco (UFPE), do programa de Pós-Graduação em Ciência da Informação. O tema central é identificar como a poesia de Abidoral Jamacaru é considerada um elemento de memória na região do Cariri Cearense, permitindo, por meio da 
representação do conhecimento, visualizar as categorias representativas da memória sobre a região subsumida nas poesias deste autor.

Nesse sentido, por intermédio dos autores recorrentes na literatura da Ciência da Informação, revisitaram-se os conceitos de memória e poesia. Esta pesquisa delimitou historicamente a análise do movimento de contracultura no Cariri na década de 1970, ao verificar as influências ideológicas dos hippies fortemente entranhadas nos modos de vestir, nos comportamentos diante da sexualidade e do corpo dos artistas da região, no qual, partiu-se do pressuposto de que essas estéticas paisagísticas foram de grande influência na representação das poesias de Abidoral Jamacaru.

Já no que tange ao artista, Abidoral Jamacaru é residente da cidade de Crato, no interior do Estado do Ceará, na denominada Região do Cariri Cearense. O poeta coleciona passagem pelos festivais da canção, os quais já compilam mais de quarenta anos de carreira. Sobre sua obra, Bida (como é popularmente chamado o poeta) segue com cinco CDs gravados (descritos em outra seção), dos quais um é uma homenagem ao poeta feita pelos artistas de sua localidade (ALVES, 2018).

O problema que moveu a pesquisa pode ser resumido na seguinte pergunta: Quais categorias representativas identificam a poesia de Abidoral Jamacaru enquanto registro memorialístico da região do Cariri Cearense? Para a resolução desta problemática, utilizou-se, como procedimentos metodológicos, a Análise de Conteúdo, com a Análise Temática, averiguando quais os contextos sociais que influenciaram na composição de suas obras.

Conforme essas informações introdutórias, o objetivo norteador deste trabalho é o de apresentar a poesia de Abidoral Jamacaru como registro memorialístico da região do Cariri Cearense.

\section{Setenta Anos de Abidoral Jamacaru: tradição e modernidade no Cairri}

A década de 1970 foi marcada por uma geração de artistas, produtores culturais e até mesmo hippies que chegavam à região do Cariri e ali se alojavam, modificavam a estrutura normativa padrão, a estética paisagística da cidade de Crato, as noções de arte e as relações de pertença desses jovens. Nesse sentido, 
seria a despersonificação que Martins (2003ํa apud MARQUES, 2005, p. 63) chamaria de "a Santíssima Trindade Nordestina": Padre Cícero, Luiz Gonzaga e Patativa do Assaré "[...] compondo um espaço profundamente marcado pela tradição [...]" (MARQUES, 2005, p. 63).

A priori, antes de adentrar nos aspectos de contradição com o espaço fortemente marcado pelo coronelismo, o Crato, em meados do século XX, foi o maior centro urbano da região Caririense. A esse respeito, Dias (2014) afirma que o Crato

[...] passa a ser representado como 'Cidade da Cultura', devido, em parte, à presença de instituições de ensino voltadas para jovens provenientes de regiões circunvizinhas que lhe ocorriam em busca da formação educacional básica, além de todo um suporte civilizatório que foi instituído justamente para dotar a cidade desse ostentativo título. (DIAS, 2014, p. 19).

Dotar a cidade de um título prestigiado envolvendo o termo cultura, não foi apenas atribuído por jovens de regiões circunvizinhas, mas também por filhos de elites que, anteriormente, iam para as capitais como Recife, Fortaleza e Salvador para se formarem e voltavam para repassar seus conhecimentos acadêmicos aos demais, o que já ocorria anteriormente ao século XX. Conforme Viana (2011) ressalta, como o seminário São José que, a partir de 1875 disseminava uma perspectiva de vida intelectual no Crato na qual:

[...] os filhos da elite podiam permanecer por mais tempo em casa e as famílias abastadas de localidades próximas podiam enviar seus filhos para estudar no Crato sem precisar deslocá-los ao Recife, Salvador, Rio de Janeiro ou Fortaleza, como era recorrente até meados do século XIX. (VIANA, 2011, p. 64).

A cidade, então, além dos elementos simbólicos da religiosidade, do baião de Luiz Gonzaga e das poéticas de Patativa do Assaré, foi se constituindo enquanto berço da cultura diante de uma disputa de forças, um campo de poder, no qual a elite construía, mas, sobretudo, aceitava-se socialmente um conjunto de regras que formavam a estrutura social da época.

Nesse aspecto, Dias (2014) adverte que: 
Os elementos discursivos, elaborados e difundidos pela intelectualidade local e que procuravam dar sustentação a esta representação, priorizavam a participação das elites, protagonistas de feitos que davam sustentação à base identitária do sujeito caririense e do conceito de região sustentado por um passado heroico. (DIAS, 2014, p. 69).

Os elementos discursivos atribuídos pelas elites começavam a inserir desníveis culturais entre as classes subalternas e a cultura elitizada. No Cariri, os burgueses que se formavam em outros Estados, com outros ideais de mundo e, ao retornarem para a sua região de origem não mais se identificavam com o padrão ainda vigente.

Na concepção de Meneses e Cordeiro (2014) as elites tradicionais da cidade elaboraram um capital simbólico que "[...] serviu não apenas para construção de uma ideia unificadora de Cariri, mas, sobretudo, como mecanismo de força nas disputas de poder local.” (MENESES; CORDEIRO, 2014, p. 80). A problemática retorna nos anos 1970 através dos movimentos de contracultura liderados por jovens que procuravam inserir modernidade no cenário artístico local, mas repetiam o desejo de identidade agregadora, mesmo tendo seu início na crítica de uma cultura elitista, em "[...] contraposição a movimentos de recusa desses modelos.” (MENESES; CORDEIRO, 2014, p. 80).

Diante disso, a cidade de Crato foi o locus das entrevistas realizadas por Marques em seu artigo intitulado: Seja moderno, seja marginal: engenhos $e$ artimanhas da contracultura no Cariri, no qual compila falas de diversos artistas e produtores culturais da região Caririense dialogando com teóricos sobre os fluxos do movimento da contracultura no ano de 1970. Segundo Marques (2008):

Essa geração de jovens artistas, da qual participaram pessoas como Rosemberg Cariry, Abidoral Jamacaru, João do Crato, Luiz Carlos Salatiel, entre outros, era formada por jovens entre 16 e 28 anos, comprometidos com as mais diversas formas de expressão artística: teatro, cinema, literatura, artes plásticas, música etc. Durante duas décadas suas produções marcaram de forma contundente a região, tanto por eventos periódicos, como a realização de $\mathbf{1 1}$ festivais da canção, lançamento de jornais ou revistas, organização de salões de mostra de expressões artísticas locais ou não, como pela realização de shows, publicação de escritos, filmes etc. Em toda essa produção estaria presente a intenção de romper com a estética, canais e conteúdo das formas tradicionais de expressão artística local, 
confrontando-se, sobretudo, com uma geração anterior de intelectuais da década de 1950, reunidos em torno de instituições locais como o Instituto Cultural do Cariri (ICC) e Sociedade de Cultura Artística do Cariri - SCAC. (MARQUES, 2008, p. 47-48, grifo nosso).

Dessa forma, um grupo social externava outros desejos: jovens artistas que não se contentavam com o "[...] ordenamento de espaços e a correção de distorções advindas do crescimento acelerado pelo qual passava a região." (DIAS, 2014, p. 122), traziam consigo contestação típica da idade e a criatividade intrínseca do fazer artístico.

Refletir a tradição como "[...] sabedoria que se transmite implicitamente, através da observação e da imitação de posturas de atitudes, das regras." (RODRIGUES, 1996, p. 306) é pensar os jovens da década de 1970 como agentes transformadores de questionamentos e propostas atrelados às diversas formas artísticas - festivais de música e passeatas de protestos, dentre outros - transmitidos fortemente através das artes, política e do comportamento juvenil.

Esse movimento de contestação partiu dos meios mais industrializados e foi atingindo, paulatinamente, a periferia do sistema capitalista numa onda irreversível, até chegar aos contornos mais distantes da 'civilização contemporânea ocidental'. (DIAS, 2014, p. 123).

Desse modo, no momento em que há pressão à tradição, os movimentos modernos de ruptura com as regras tornam-se maiores, mesmo essa concepção não sendo regra em si. Numa analogia pertinente para reflexão, Hall (2011, p.7) destaca que: "as velhas identidades, que por tanto tempo estabilizaram o mundo social, estão em declínio, fazendo surgir novas identidades e fragmentando o indivíduo moderno, até aqui visto como um sujeito unificado."

No que tange a identidade, Hall (2011) sustenta que

[...] a identidade é formada na 'interação' entre eu e a sociedade. O sujeito ainda tem um núcleo ou essência interior que é o 'eu real', mas este é formado e modificado num diálogo contínuo com os mundos culturais 'exteriores' e as identidades que esses mundos oferecem. (HALL, 2011, p. 11-12). 
Como forma de exemplificação do descrito por Hall (2011) com o objeto de estudo em pauta: os jovens caririenses se projetam nas identidades culturais que lhes são apresentadas, ao mesmo tempo em que internalizam as simbologias e valores, tornando-se parte deles, contribuindo para a formação da sua subjetividade com os lugares objetivos que ocupam na estrutura social e cultural.

Nesse aspecto, Dias (2014) descreve que os herdeiros dos representantes da tradição local resolveram romper com os laços da cultura dominante e gerar experiências estéticas atreladas ao movimento da contracultura vigente na época.

A produção artística-cultural desse movimento específico era demarcada em romper com a estética, com as formas tradicionais de expressão local. Os festivais da canção eram propulsores das novas produções artísticas, as quais refletiam no Cariri, especificamente no Crato. Desse modo, era preciso criar canais de comunicação entre si, como forma de expansão e visualização das suas artes. Marques (2008) salienta que a transformação da cidade só era possível através da criação de canais de visibilidade para os jovens caririenses, desencadeado pelos produtores culturais em que, paralelo à concepção de estar antenado com o mundo, "era mister fazer-se presente na cidade" (MARQUES, 2008, p. 48).

Nesse sentido, o universo em que os artistas estavam inseridos era permeado por diversas visões de mundo, provocando uma vontade de desterritorialização atrelada aos canais de distribuição de signos estabelecidos e à vontade de marginalidade, tão característicos à época. Os modernos marginais não estavam fora do campo de poder, mas, eram resultantes de novas junções de poder.

Conforme o descrito, permeado pelos canais de comunicação vigentes da época, pelos festivais da canção e pelos jogos de poder, resultantes desses acontecimentos, foi sendo desenvolvido o movimento de contracultura na região do Cariri Cearense. Tal movimento foi pautado na instauração de novas redes de distribuição de signos e pela obsessão em tornar-se antenado com o mundo (ALVES, 2018). 
Numa comparação pertinente, se nos anos anteriores os jovens saiam da sua localidade em busca de aperfeiçoamento profissional e acadêmico, nos anos 1970 voltariam com o cabelo em desalinho, com novos discos e condutas diante da sexualidade e do corpo. As imagens que compunham o cenário de 1970, direta ou indiretamente, refletem na poética do artista, ao pensar que os atos sociais são passíveis de ser representados em algum tipo de estrutura narrativa, a qual pode provocar catarse ao artista.

Diante do descrito, Abidoral Jamacaru foi sujeito ativo no movimento de ruptura com o padrão normativo vigente da época. $\mathrm{O}$ poeta participou de festivais da canção ocorridos em Crato, na perspectiva de disseminar a sua arte através da música. Conforme Jamacaru, em entrevista cedida ao pesquisador Alves (2015), respalda o dito anterior:

[...] aparecia nos festivais da canção aqui no Crato, naquele tempo era uma febre de festival havia o Festival da Record, da Tupi. E a gente já viu tudo isso, foi uma explosão no mundo inteiro. [...] O festival internacional da canção que a globo posteriormente fez. Então nesse clima todo começou aparecer festivais de várias cidades do interior, do Brasil e o Crato foi uma delas que deu a muita gente a oportunidade de mostrar que era possível fazer música no interior. $\mathrm{E}$ aí foi onde a gente, provavelmente, teria deslanchado. (ALVES, 2015, p. 46).

Atualmente com 70 anos de idade, o poeta coleciona três CDs gravados, dentre composições próprias e individuais; ao mesmo tempo, o escritor não se distingue entre poeta e músico, segundo Jamacaru - ainda em entrevista cedida a Alves (2015):

Eu prefiro não definir, prefiro deixar que as pessoas definissem. Eu não gosto de definir não. Eu me utilizo da poesia, claro que quando você vai escrever uma letra que tem sentido poético... Poesia nasce consigo e de uma forma latente [...] Mas eu via em cada uma, coisas bonitas, coisas interessantes, algumas... Que às vezes nem é tão a questão bonita, é questão de esclarecimento, o simples fato da estética mesmo, o simples fato de você comunicar através da estética. É diferente, como eu estou aqui com você conversando. Quando a poesia trabalha com a síntese, isso é interessante. Inserido... Porque o pessoal gosta de separar letra de poesia né? Eu diria que em minhas letras também tem poesia, algumas podem até não terem, são simplesmente letras de música, mas em algumas tem poesia e depois você se manifesta à medida que há provocações. (ALVES, 2015, p. 46). 
Percebe-se, a priori, o quanto os elementos paisagísticos, advindos das experiências de vida do autor e, sobretudo no tempo da sua juventude, são elementos de representação na poesia de Abidoral Jamacaru. Também, não tendo como perspectiva classificar as diferenças entre poesia e música, a fala de Abidoral foi de suma importância para romper com a regra academicista de nortear as diferenças entre música e poesia (o que é importante, mas não é a delimitação deste trabalho), proporcionando ao sujeito da pesquisa autonomia em sua concepção.

Desta forma, compreende-se o Cariri como um terreno fértil de criatividade, em que artistas começaram a ter visibilidade nas suas produções artísticas a partir do rompimento de uma estética pré-estabelecida, promovida por jovens com roupas, cabelos e intelectualidade modernistas frente ao período de 1970. Percebeu-se, ainda que brevemente, as disputas de poder e os grupos elitistas que participavam do movimento de contracultura.

\section{Memória e poesia sob a perspectiva da Ciência da Informação}

Esta seção identifica o conceito de memória, pontual e especificamente relacionado aos objetivos e perspectivas da pesquisa. Assim, no que tange à memória, perpassa-se por algumas trajetórias históricas que confluem com o início da poesia, através dos estudos da área de Ciência da Informação.

De acordo com Le Goff (1990) a memória pode ser definida como uma "[...] propriedade de conservar certas informações, remete-nos em primeiro lugar a um conjunto de funções psíquicas, graças às quais o homem pode atualizar impressões ou informações passadas, ou que ele representa como passadas." (LE GOFF, 1990, p. 423).

Na visão de Detienne (1988)

[...] a palavra cantada é inseparável da memória: na tradição hesiódica, as Musas são filhas de Mnemosýne; em Kios, elas levam o nome de 'rememoranças' [...], são elas também que fazem o poeta 'lembrar-se'. (DETIENNE, 1988, p. 17).

Além disso, existiam outras deusas que representavam cada aspecto da poesia. Detienne (1988) informa que cada deusa levava alguns processos da 
poesia. Meléte, Mnéme e Aoide; cada uma delas levava o nome de um aspecto essencial da função poética. O autor relata:

Meléte designa a disciplina indispensável ao aprendizado do oficio de aedo; é a atenção, a concentração, o exercício mental. Mnéme é o nome da função psicológica que permite a recitação e a improvisação. Aoide é o produto, o canto épico, o poema acabado, termo último da Meléte e da Mnéme. (DETIENNE, 1988, p. 17).

Corroborando com o supramencionado, Lopes (1996) esclarece que:

Na Grécia, nos seus primórdios, a poesia identificava-se com a memória. Ela era um dom das musas, filhas de Mnemosina, a Memória. $\mathrm{O}$ canto dos poetas é algo que não lhes pertence, que não é escolhido, mas que também não é convertível em simples dádiva, na medida em que não se deixa reduzir a um dito transmissível sem falha: ecoa nele uma origem secreta e indecifrável que o lança num devir infinito. O poeta detém assim um poder superior, o de imortalizar ou condenar ao esquecimento, que lhe confere uma autoridade particular. (LOPES, 1996, p. 155).

Na Grécia Antiga, a relação da memória e poesia não se esgota. O surgimento da poesia lírica retira a poesia da sua ligação com o sagrado, ocorrendo o processo de laicização.

Os poetas líricos desinteressam-se das histórias de deuses e heróis, e voltam-se para a contingência na qual se inscreve a vida do indivíduo; procuram, como diz Arquíloco, compreender o ritmo da ascensão e da queda humana (LOPES, 1996).

É a partir de Simônides que a memória aparece totalmente laicizada, transformando-se em técnica que opera no tempo enquanto atividade profana (DETIENNE, 1988). Os poetas então começam a escrever sobre outros aspectos sociais, seja sobre o amor, política, do ato subjetivo do eu, dentre outros temas.

Ao identificar que a poesia, no decorrer da sua história, desassocia-se do sentido temático arraigado ao divino, e insere ideologias às posições sociais, presume-se uma representação social de valor simbólico, como forma de representar eventos, objetos etc., elucida um viés de investigação além do aspecto estético. 
Nesse sentido, McGarry (1999) informa que para facilitar a memória e a recordação, a tradição coletiva resguardava-se em forma de poesia e prosa rítmica. Ainda adverte que a poesia é mais fácil de lembrar que a prosa, uma vez que os sentimentos e a sua expressão harmoniosa ajudam a memória a localizar a "[...] maior unidade manejável de significado" (MCGARRY, 1999, p. 67) contribuindo para a sua permanência no cérebro.

Dessa forma, a poesia rítmica facilita na imposição social de ordenar o conhecimento disponível, seguindo a lógica de que a ordem antecede o controle. McGarry (1999) então enfatiza: "Portanto, a forma de representação do conhecimento estava nas formas mais facilmente memorizáveis e recitáveis do mito, da poesia e dos provérbios, canções e lendas." (MCGARRY, 1999, p. 67).

Conforme o explanado, o ofício do poeta não é de narrar o que aconteceu, mas de representar o fato que poderia ter acontecido. $\mathrm{O}$ poeta, como grande educador da humanidade, consiste na concepção de que a verdade ou a origem se diz, ou se promete, na linguagem (LOPES, 1996).

As palavras possuem significados próprios, entender as entrelinhas é utilizar-se de um método analítico de vislumbrar para além do que é exposto. Não se trata de qualquer análise, mas de utilizar-se de mecanismos metodológicos que permitam circundar o máximo possível a compreensão do registro escrito.

Nesse contexto, para Silva (2016), sobre a Teoria Matemática da Informação na Ciência da Informação, pensar na ideia de materialidade da informação está nas possibilidades de mensurar os suportes de informação como documentos, artefatos e a capacidade de reprodução de mensagens em aparelhos analógicos e, recentemente, digitais.

Ao identificar a poesia como registro memorialístico, afirma-se que há objetos de memória porque não há mais meios de memória (NORA, 1993). Nora (1993) é enfático ao afirmar que "Os lugares de memória são, antes de tudo, resto." (NORA, 1993, p. 12). Nesse sentido, o autor insere uma acepção de que não há memória espontânea, de que é preciso criar arquivos, manter aniversários, organizar celebrações, notariar atas, registrar escritos em determinado suporte, porque não são ações naturais (NORA, 1993). 
Nora (1993), adverte que a memória conheceu duas formas de legitimidade: histórica ou literária, "Elas foram, aliás, exercidas paralelamente, mas, até hoje, separadamente." (NORA, 1993, p. 28). O autor provoca a relembrança da ligação que a memória teve em seu início com sua capacidade histórica, de reconstrução e atrelada ao aspecto poético, literário (NORA, 1993).

Já para Smolka (2000), a memória se relaciona com a poesia seguindo o que ele denomina de "memória rítmica", então, "[...] a maneira mais direta de imitação, de memorização, de sustentação da tradição. A Musa, voz da instrução, é também a voz do prazer. A memória toda de um povo é poetizada." (SMOLKA, 2000, p. 169). Poesia no sentido de comunicação conservada. Prática da memória na palavra (en)cantada, na poesia. A memorização da tradição poetizada necessita da recitação constante e reiterada (SMOLKA, 2000).

Contextualizando os estudos de memória na Ciência da Informação, é importante destacar a sua múltipla aplicação não apenas em nível conceitual, mas de como os autores da área têm trabalhado na prática. Diante da literatura, e de acordo com Oliveira e Rodrigues (2011), parece não haver um conceito de memória único, consequentemente, uma aplicação única desse termo nos estudos da área mencionada.

Dessa forma, pretende-se ponderar como a Ciência da Informação vem discutindo a memória, elencando as vertentes trabalhadas com fins de contexto. Em um artigo que traça como a memória está sendo trabalhada nos programas de Pós-Graduação em Ciência da Informação nos anos de 1972 a 2005, Oliveira e Rodrigues (2011) concluem que a Ciência da Informação no Brasil tem se apropriado “[...] em apenas um dos aspectos identificados na literatura internacional, o aspecto social.” (OLIVEIRA; RODRIGUES, 2011, p. 311).

No artigo, os autores Oliveira e Rodrigues (2011) apoiam-se às categorias preestabelecidas a partir do trajeto teórico de Smit e Tálamo em 2006, que ressaltam o tratamento da memória em três categorias: memória humana, em que os trabalhos se dirigem para o foco na faculdade humana de conservar, recordar e transmitir informações, bem como a relação com os processos cognitivos. Memória artificial, na qual os trabalhos apresentam o foco na 
memória exteriorizada como extensão da memória humana, intermediada e adicionada por recursos tecnológicos, ou como procedimento técnico que permite a sua fixação e facilita sua recuperação. E, por último, a memória social, com trabalhos cujo foco recai sobre registros de informação, como memória socialmente construída, sejam eles institucionais (arquivos, bibliotecas e museus) ou não.

Diante do escopo do trabalho, ainda conforme Oliveira e Rodrigues (2011), a partir da verticalização dos dados de sua pesquisa podem considerar que nas Teses e Dissertações dos Programas de Pós-Graduação em Ciência da Informação "Os termos mais citados remetem a uma perspectiva social da memória [...]" (OLIVEIRA; RODRIGUES, 2011, p. 319). Em termos de resultado, concluem:

a) há um caráter periférico do tema da memória, tanto nacional como internacional;

b) a literatura internacional tem interesse pelo estudo de novos suportes para o registro de informação "[...] quanto à capacidade de armazenagem e à adequação das mídias aos sistemas de informação [...]" (OLIVEIRA; RODRIGUES, 2011, p. 319). Essa, por sua vez, resulta em estudos da memória artificial;

c) memória como capacidade humana resultou na área menos explorada na Ciência da Informação, tanto na literatura internacional como na nacional.

Diante das concepções, parece haver uma tendência dos estudos relacionados à memória e informação, considerando as informações registradas (documentos), em diversos suportes com relevância social em diferentes níveis: local, regional e nacional. Essa relevância se justifica na tentativa de reconstrução da memória e da formação da identidade a partir de registros que, assim, exigem organização, preservação e divulgação. Há, também, na identificação da pesquisa, o fator informação interceptando os trabalhos de memória seja qual for a abordagem adotada: memória humana, artificial ou social. 
A pesquisa de Oliveira e Rodrigues (2011) destaca as categorias de abordagem da memória na Ciência da Informação, as quais têm sido utilizadas em tempos atuais, como por exemplo, pesquisas de memória e cultura material, enquanto representação da memória numa perspectiva social, como salientado por Azevedo Netto (2004).

Desse modo, aqui não se pretende traçar as diversas abordagens e categorias da memória na Ciência da Informação, mas inseri-las, a partir de Oliveira e Rodrigues (2011), partindo da compreensão de que as análises de cada autor, suas correntes teóricas, bem como seus programas de pós-graduação, tendem a abordar a memória de modo diverso, no qual uma não se sobressai nem sobrepõe à outra.

Neste estudo, tem-se a característica da memória enquanto registro memorialístico de caráter cultural, como entende Azevedo Netto (2004) quando aponta a representação da memória e identidade cultural (as poesias Abidoral Jamacaru materializadas em CDs), “[...] perpassadas pela questão da representação, já que é através dos artefatos que são usados cotidianamente por um grupo que essa identidade pode ser visualizada e até mesmo, cristalizada no tempo.” (AZEVEDO NETTO, 2004, p. 08). Conforme explanado, salientaramse as vertentes temáticas da memória no escopo da Ciência da Informação de modo amplo, cabendo maiores discussões em trabalhos futuros.

Sendo assim, todo o referencial teórico exposto permitiu vislumbrar a poesia na sua relação com a memória, mesmo que de modo breve (e pela extensão da seção de tratamento dos dados). Pode-se, mesmo que inicialmente, provocar a discussão da representação social no poema, no entanto, a abordagem do registro de memória será dialogada com o sujeito deste trabalho, Abidoral Jamacaru.

Registrado fisicamente em três CDs de sua autoria com escritos autorais e coletivos: Avallon, de 1986, O Peixe, de 1998, e Bárbara, de 2008, compõem o conjunto da obra do autor, os períodos são de acordo com seus lançamentos.

Inserir o poeta neste discurso permite identificar a materialização da sua arte, ao mesmo tempo em que concebe, mesmo que inicialmente, um registro de vivência, de representação da estética de suas experiências. Ratifica-se que, 
neste momento, não é cabível reconhecer a sua obra artística como memória do Cariri, contudo, é inicialmente caracterizado como registro de memória, ao entender registro o suporte no qual algo se fixa, e, ao compreender a memória como lembranças do passado que podem ser gravadas em determinado suporte.

\section{Procedimentos metodológicos}

A metodologia desta pesquisa, como inicialmente referenciada, utiliza-se da Análise de Conteúdo, tendo como procedimento metodológico a Análise Temática. Nessa acepção, será descrito como o trabalho se desenvolveu a partir desta metodologia, mais do que puramente conceituá-la. O importante nesta pesquisa, para além do conceito, é a sua explanação, explicitando de qual maneira foram feitas as análises das poesias, e como resultou na representação do conhecimento por intermédio dos mapas conceituais.

Para Bardin (1997), Análise de Conteúdo é uma técnica de analisar a comunicação. Esta última é entendida por Franco (2005) como um fenômeno composto por cinco elementos básicos:

[...] uma fonte ou emissão, um processo decodificador que resulta em uma mensagem e se utiliza de um canal de transmissão; um receptor, ou detector da mensagem, e seu retrospectivo processo decodificador. (FRANCO, 2005, p. 20, grifo do autor).

Na presença dessa afirmativa, a Análise de Conteúdo se classifica em três fases segundo Bardin (1997):

a) a pré-análise, sendo esta caracterizada como a aproximação do objeto a ser estudado, organizando-o, sistematizando as ideias iniciais. Essa operacionalização consta com:

- leitura flutuante, o primeiro contato com o objeto, para o seu conhecimento;

- escolha dos documentos, delimitando o que será analisado (nesta parte adentra a amostra situacional);

- formulação de hipóteses e objetivos; 
- elaboração de indicadores, por intermédio da seleção dos documentos em análise.

b) a exploração do material, fase na qual são extraídas as informações dos documentos para interpretações e inferências, classificar, categorizar são aspectos fundamentais;

c) o tratamento dos resultados, a inferência e interpretação, constituemse de análise rigorosa diante das classificações já desenvolvidas em etapas anteriores

Conforme as etapas descritas de Análise de Conteúdo, utilizou-se análise temática. Bardin (1997) salienta:

Fazer uma análise temática consiste em descobrir os $<<$ núcleos de sentidos $>$ que compõem a comunicação e cuja presença, ou frequência de aparição pode significar alguma coisa para o objetivo analítico escolhido. (BARDIN, 1997, p. 313, grifo do autor).

Após as análises, foram desenvolvidos mapas conceituais entendo-os como representações gráficas do conhecimento (gerando uma representação do conhecimento) que permitem a compreensão dos conceitos e do conhecimento do autor diante do objeto analisado, no caso, as poesias.

Os mapas conceituais (estruturados de forma lógica e hierárquica) subsidiarão na análise das poesias como representativas da região do Cariri Cearense, a partir do entendimento dos conceitos identificados após a técnica de análise temática. Serão inseridos de modo a representar o conhecimento desenvolvido durante todo o processo de tratamento dos dados, permitindo a sua visualização de forma lógica.

Na reflexão de Lima (2004), a utilização do mapa conceitual, para o cientista da informação, torna-se instrumento importante para ajudá-lo compreender e lidar com estruturas informacionais. 


\section{Resultados e discussões: a representação do conhecimento das poesias de}

\section{Abidoral Jamacaru}

A operacionalização se desenvolveu da seguinte maneira: Preparação das informações; transformação do conteúdo em unidade de significado (Unitarização); categorização; descrição e interpretação.

A primeira etapa de análise identificou as diferentes amostras de informação. Deste modo, foram lidas as trinta e nove (39) poesias, compondo um total de trinta e sete (37), pois haviam duas que foram inseridas em outros trabalhos do autor.

Ao proporcionar o recorte dos textos poéticos, a categorização ficou da seguinte maneira: quatro poemas de categoria da natureza e uma política, sendo elas: Pra ninar o Cariri; Cariri - o hino; Consolança; Vou no Vento (categoria natureza) e Bárbara (categoria política).

Em concordância com as amplas categorias, a Análise de Conteúdo permitiu criar uma subcategoria, a qual foi denominada de Aspectos Regionalistas inserindo nela os poemas das categorias natureza e política, tendo como premissa os aspectos regionais como indivíduo(s) representativo(s) da região, ou de caráter da natureza como, entre outros, a flora e a fauna (ALVES, 2018). Definida a amostra situacional, seguiu-se com a releitura e interpretação das informações, identificando os núcleos de sentidos nos poemas e compreendendo as entrelinhas dos versos intercalados com a narrativa do autor e com a literatura científica quando pertinente.

\subsection{Bárbara}

Escrita em parceria com seu irmão, Pachelly Jamacaru, Abidoral Jamacaru retrata em Bárbara aspectos da história de uma ativista política feminina da região do Cariri, mais especificamente na cidade de Crato. De acordo com os seguinte trechos:

$\mathrm{Na}$ Caiçara tu brotaste/Vale dos índios Açu/No pau seco floresceste/Perfumando o Vale Sul /Hoje flora Sucupira, Oiticica, Mororó/Filhos de tuas palavras. (JAMACARU; JAMACARU, 2008). 
Os trechos do poema representam o nascimento de Bárbara, o local em que residiu e alguns seguidores de sua ideologia política. Conforme o Mapa Conceitual 1, Bárbara Pereira de Alencar nasceu no dia 11 de fevereiro de 1760, em uma casa-grande de Caiçara, na cidade de Exu, em Pernambuco. Filha de Joaquim Pereira de Alencar e Theodora Rodrigues da Conceição, Bárbara, ainda adolescente, migrou com a família para a Vila do Crato, no Ceará (VAINSENCHER, [2010?]).

Já na fase adulta, aos vinte e dois anos, Bárbara de Alencar casou-se com o descendente português e comerciante de tecidos José Gonçalves dos Santos (SOUSA, 2015) e instala-se na propriedade do sítio Pau-Seco (VAINSENCHER, [2010?]). Conforme Araújo (2002 apud SOUSA, 2015) Bárbara de Alencar teve cinco filhos: João Gonçalves de Alencar (27/02/1783), Carlos José dos Santos Alencar (27/08/1784), Joaquina de São José (29/12/1787), Tristão Gonçalves Pereira de Alencar (17/09/1789) e José Martiniano de Alencar (18/10/1794), este último, pai do escritor José de Alencar. 

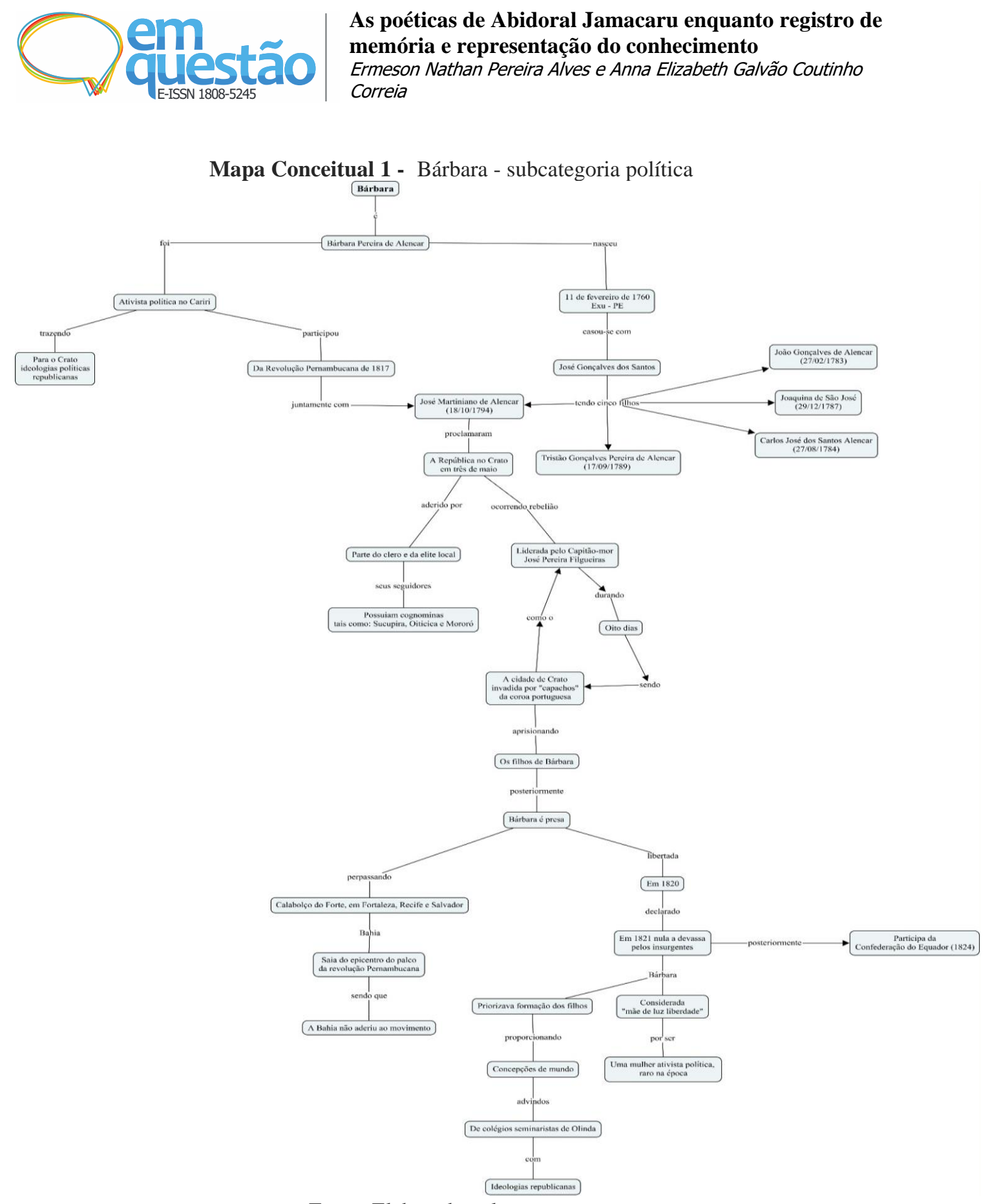

Fonte: Elaborado pelos autores.

Em 1817, já viúva, Bárbara de Alencar administrava os negócios da família e tinha forte influência na vida política e cultural da região do Cariri. Participou da Revolução Pernambucana de 1817, trazendo para o Cariri as ideologias republicanas disseminadas em Pernambuco. Segundo Luna (2015):

[...] seu apoio ao movimento terá grande repercussão. Trazido por seu filho, José Martiniano, o movimento rebelionário proclamará a República, no Crato, em três de maio, com adesão de parte do clero e da elite local. No entanto, em poucos dias a repressão avança sobre a região, liderada pelo Capitão-mor José Pereira Filgueiras, 


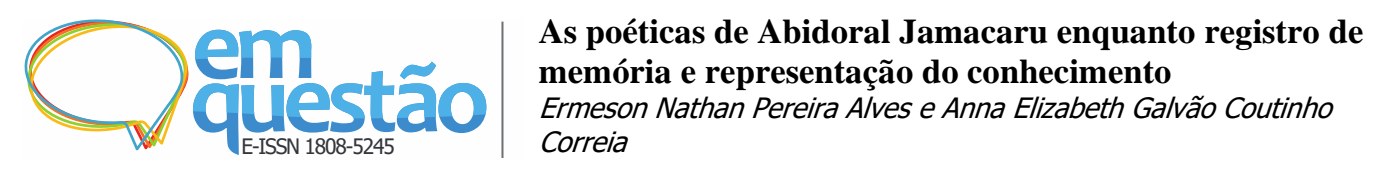

inimigo político da família Alencar. Primeiramente são presos os filhos de Bárbara; dias depois, ela é aprisionada e levada para o calabouço do Forte, em Fortaleza. Daí penará em prisões de Recife e Salvador. Libertada em fins de 1820, somente em inícios de 1821 os tribunais declaram nula a devassa contra os insurgentes. (LUNA, 2015, p. 1, grifo nosso).

O trecho 'Hoje flora Sucupira, Oiticica, Mororó, filhos de tuas palavras', refere-se aos integrantes do movimento republicano na cidade de Crato juntamente com Bárbara de Alencar. Segundo a matéria do Diário do Nordeste, assinada por Domingos Pascoal (2008), os participantes escondiam-se atrás de cognomes como Alecrim, Anta, Araripe, Aroeira, Baraúna, Beija-flor, Bolão, Carapinima, Crueira, Ibiapina, Jaguaribe, Jucás, Manjericão, Mororó, Sucupiras, Oiticica.

Bárbara de Alencar priorizava na formação de seus filhos conhecimentos sociais, históricos e políticos, para que os mesmos pudessem criar suas concepções ideológicas diante do mundo. Nesse sentido, o Seminário de Olinda foi a instituição de educação religiosa que teve fator primordial para o engajamento da família Alencar na militância política, por ser o local irradiador dos ideais iluministas. Todavia, destacava-se como instituto segregador da elite, por seu alto dispêndio (KELYANE, 2015).

A seguinte oração: "Mãe de luz liberdade", refere-se a uma mulher com estratégia política definida, fazendo com que o Cariri se destacasse nos “[...] movimentos políticos emancipacionistas de caráter liberais e republicanos, eclodidos em Pernambuco.” (DIAS, 2014, p. 17).

Em entrevista cedida ao programa De lá pra cá, em 2010, o historiador Denis Bernardes, da Universidade Federal de Pernambuco, relaciona Bárbara de Alencar, de modo amplo, como heroína do Brasil. Não apenas a matriarca, mas todos os envolvidos que se engajaram na revolução foram heróis.

Novamente, os autores do poema Bárbara correlacionam a matriarca nordestina com as agruras do porvir de uma audácia frente aos movimentos políticos de 1817 , como evidencia o trecho a seguir: 
Toda luta tem perigo e inspira um afã/Uma vida tem mistério conta a cor de uma romã/Era Bárbara, dona Bárbara/Alma linda no perdão/Muito Bárbara mente bárbara/Te aceno na canção. (JAMACARU; JAMACARU, 2008).

O núcleo em destaque evidencia que toda luta inspira uma ansiedade, na conjuntura em que se apresenta, a vitória é o afã do movimento político, nesse caso, Bárbara de Alencar proclama a república na cidade do Crato, a qual dura um período de oito dias, pois foi invadido pelos capachos da coroa portuguesa, ao mesmo tempo em que é perseguida e presa.

O historiador Denis Bernardes, ainda conforme a entrevista concedida ao De lá para cá (2010) explica que as mudanças de capitais foram devido a uma estratégia repressiva, com o objetivo de manter Bárbara de Alencar distante das suas ligações políticas e suas parentelas.

O verso 'Muito Bárbara mente bárbara' é um trocadilho com a palavra bárbara, tendo sentido de ser uma mente brilhante na coragem de expressar suas ideologias políticas, o afrontamento às questões sociais de 1817 e, sobretudo, a persistência na militância política (sua participação na Confederação do Equador 1824) após serem libertos, não apenas Bárbara, mas seu filho Alencar.

\subsection{Pra ninar o Cariri}

Abidoral Jamacaru em Pra ninar o Cariri descreve a representação da Chapada do Araripe de forma singela, desde o seu amanhecer até ao anoitecer, demonstrando uma característica afetiva ao local, que se encontra retratada no

\section{Mapa Conceitual 2.}

A natureza descritiva a que o poeta Abidoral Jamacaru se refere é caracterizada como a flora e a fauna da Chapada do Araripe, bem como fenômenos da natureza: "O sol doura o cume verde/Da chapada do Araripe/Sonolenta a tarde cai/Noite vem ninar o Cariri." (JAMACARU, 1988).

É importante salientar que a Chapada do Araripe se localiza na porção central do Nordeste brasileiro, com aproximadamente 603.996,9 ha, ela perpassa e limita os Estados do Ceará, ao Norte, do Pernambuco, ao Sul e do Piauí, a Oeste. 
Nesse sentido, quando Abidoral Jamacaru no primeiro verso descreve o 'sol dourando o cume verde', o cume não é existente na Chapada. No entanto, pelo viés semântico da palavra, foi inserido de modo a representar o ponto mais alto da visão que se tem da Chapada, pois o conjunto das suas formas estruturais é destacado em planaltos sedimentares e planaltos cristalinos.

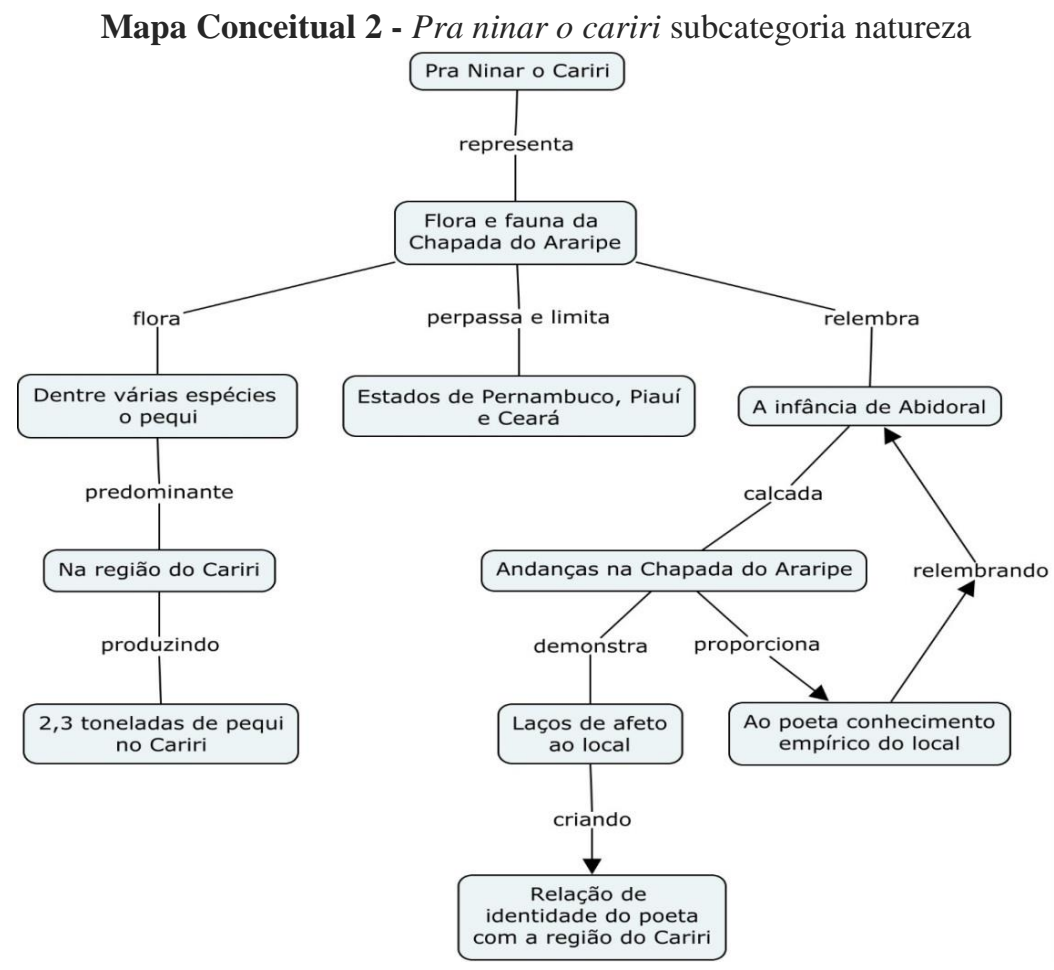

Fonte:Elaborado pelos autores.

No verso 'Sonolenta a tarde cai', seguido de seu complemento 'Noite vem ninar o Cariri’ enfatiza-se o anoitecer, em que animais e plantas vão 'dormir', como se apresenta a seguir: "Dorme o canavial/Marmeleiro, piquizal/E as palmeiras do coco babaçu." (JAMACARU, 1986).

Canavial é a plantação de cana, marmeleiro, pequizal e palmeiras do coco babaçu são também muito característicos da região do Cariri, mas não apenas na região, uma vez que em Goiás, por exemplo, há muitos pés de pequis. Entretanto, ao ser relacionado ao estudo da região do Cariri é pertinente advertir que consoante à matéria do Diário do Nordeste, assinado pelo repórter Antônio Vicelmo, em 2007, uma das metas de produtores da região já referida é aproveitar todo o potencial do pequi. Ainda segundo Vicelmo (2007), em termos 
numéricos o Cariri produz 2,3 milhões de toneladas de pequi por safra, de janeiro a abril, sendo o maior produtor da região a cidade de Crato com 1.684 toneladas, seguida de Santana do Cariri com 295 toneladas, Jardim com 135 toneladas, Barbalha com 99 toneladas e Missão Velha com 95 toneladas. Sendo uma produção que representa a inserção de recursos na região no valor de $\mathrm{R} \$$ 1,62 milhão.

A matéria do Diário do Nordeste (VICELMO, 2007) evidencia o quanto essa planta, fortemente presente na região, na Chapada do Araripe, está sendo discutida na ciência, sobretudo no que se refere a sua importância social e econômica.

Em seguida, Abidoral Jamacaru novamente recorre ao anoitecer no Cariri ao se referir à maliça, criança e ancião: "Fecha a folha o malissal/Dorme em paz criança e ancião.” (JAMACARU, 1986).

Maliça também é conhecida como dormideira e sensitiva, este tipo de planta se fecha ao ser tocada, direcionando a sua água para um espaço entre as células. De modo singelo, o poeta representa aspectos da flora e da fauna do Cariri relacionando, constantemente, ao amanhecer do dia e ao entardecer seguido da noite. É perceptível um laço afetivo com o lugar, pois são relatados as plantas e alguns animais da Chapada do Araripe que se presume a hipótese: o indivíduo é dotado de um conhecimento científico, com referências teóricas sobre o local, ou um conhecimento advindo das relações empíricas com o ambiente. Nesse caso, pressupõe-se que o poeta seja um homem da empiria, ao relembrar a sua infância. Em entrevista cedida ao pesquisador Alves (2015), Abidoral Jamacaru relata:

[...] quando eu era criança, eu andava muito na chapada do Araripe e andava muito nos rios do Crato, eram rios limpos nessa época, tomei muito banho nos rios do Crato, nos açudes. E também que eu gostava de andar nas florestas, eu sempre tive um conhecimento muito sobre os habitantes da floresta, os animais, as plantas, essas coisas, os pássaros, a chapada e aqui mesmo no pé da chapada do Araripe, esse vale Caririense, eu sempre tive muito esse contato. (ALVES, 2015, p. 61, grifo nosso).

A narrativa do poeta demonstra o afeto com a Chapada do Araripe e os rios do Crato, que no período de sua infância eram limpos. No trecho grifado 


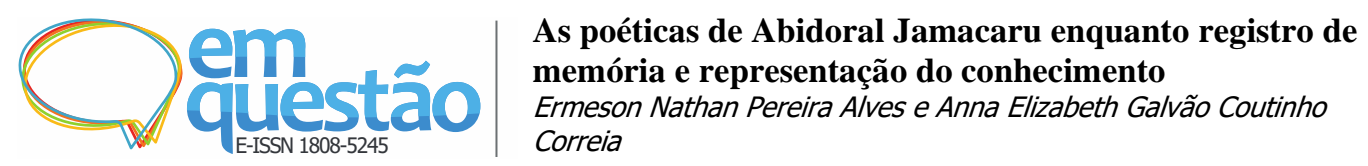

acima, percebe-se uma ligação com a terra na fala de Jamacaru e uma análise da mesma permite compreender que há uma memória afetiva do lugar, indo além da memória e informação sobre a região e da Chapada do Araripe.

Em seguida há uma sequência de denominações de alguns animais que "passeiam” pela Chapada do Araripe: “[...] claros urubus-reis, vim-vim, jacu [...]/Zabelê, cigarras, papas-vento, guachinins, rolinhas/Cascavel, guará, já vão dormir." (JAMACARU, 1986).

Especificar cada um dos animais não é vertente trabalhada nesta pesquisa, mas foram inseridos na perspectiva de demonstrar o conhecimento do poeta em relação aos animais presentes na sua região, evidenciando uma relação de identidade com o local. Desta maneira, as narrativas do autor na entrevista juntamente com as técnicas de análise de conteúdo permitem identificar que a memória afetiva ao local é perpassada pela própria memória e identidade da região.

\subsection{Consolança}

De autoria de Eugênio Leandro e Osvaldo Barroso, a narrativa escrita está inserida na obra de Abidoral Jamacaru. A poesia em análise apresenta algumas nuances do desmatamento (Mapa Conceitual 3), bem como a matança de animais da região do Cariri: "Mas, se cortaram/O pé de juazeiro/Menina não chore/Se mataram o sabiá /Não chore não.” (JAMACARU, 1998). 


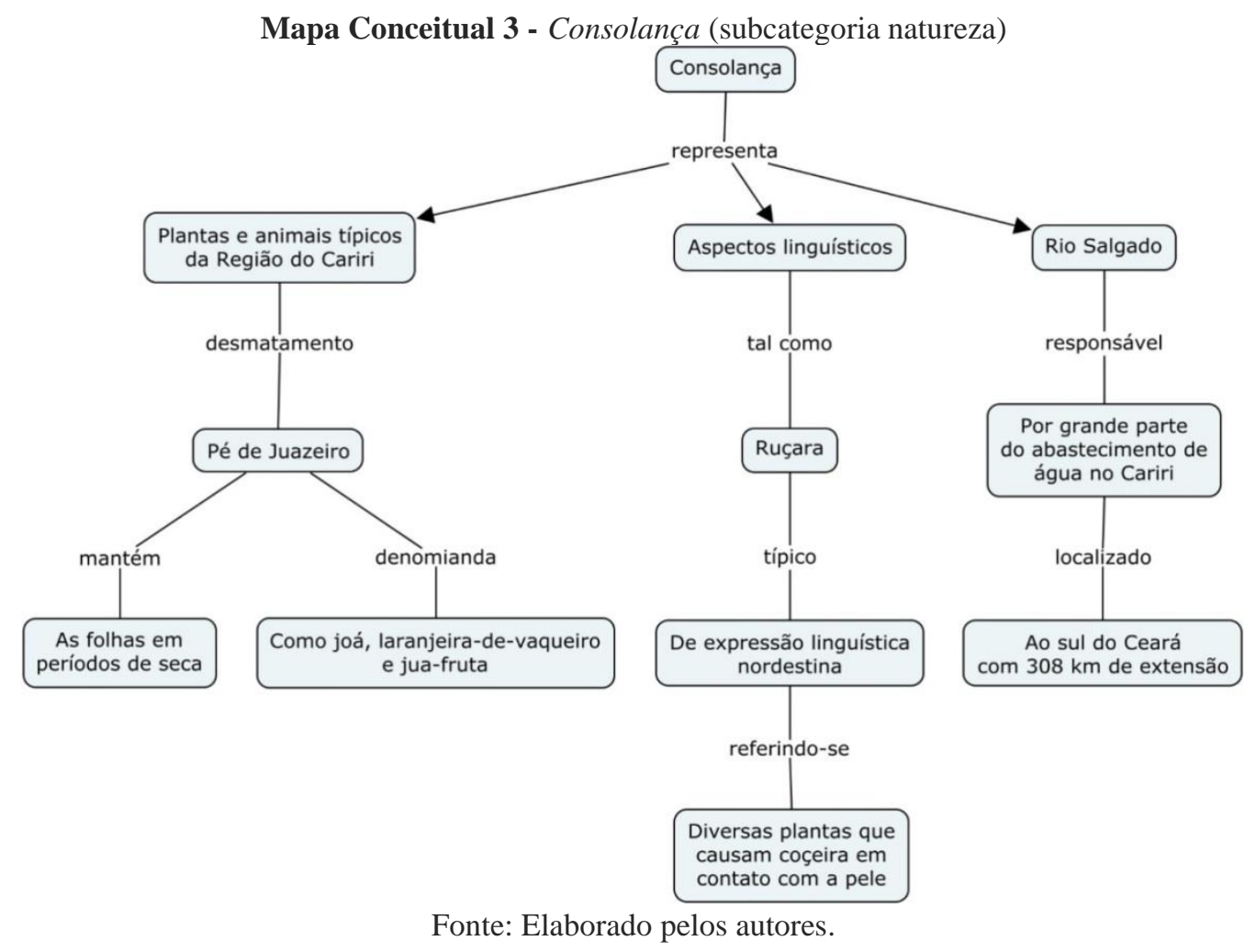

A planta juazeiro, segundo o site Escola Superior de Agricultura 'Luiz de Queiroz' (ESALQ, [2010?], da Universidade de São Paulo (USP) é denominada também como joá, laranjeira-de-vaqueiro e juá-fruta. Árvore com dez metros de altura e copa grande, possui fruto amarelado do tamanho de uma cereja e pode ocorrer em caatingas dos sertões (ESALQ, [2010?]). Ainda de acordo com o site, é uma das árvores que no período de seca nas caatingas permanece com as folhas (ESALQ, [2010?]). Em seguida, há uma consolação para a menina, sujeito do discurso da poesia, com o sol que permanece banhando o milho num roçado seco.

Em seguida o trecho "Ainda tem ruçara/Pra nos inquietar." (JAMACARU, 1998) refere-se a uma coceira produzida por diversas espécies de plantas em contato com a pele. É um tipo de linguagem nordestina expressa no verso, demonstrando as características linguísticas do local. O poeta então se refere às águas dos rios: Se secaram os rios/Inda assim não chore/As águas desse mar/Ninguém acaba não.” (JAMACAU, 1998).

Pode-se pressupor que os trechos em destaque se referem ao Rio Salgado, que é responsável pelo abastecimento no Cariri, de acordo com a 
matéria publicada pelo Diário do Nordeste (SANTOS, 2008). Segundo a repórter da matéria sobre o Rio Salgado, Elizângela Santos (2008), a Sub-Bacia do Salgado integra a Bacia do Rio Jaguaribe. Encontra-se localizada ao sul do Ceará, possuindo drenagem de $12.865 \mathrm{~km}^{2}$, sendo o Salgado o principal rio com $308 \mathrm{~km}$ de extensão (SANTOS, 2008).

A matéria ainda informa que o Salgado é o responsável por grande parte do abastecimento da água na região do Cariri (SANTOS, 2008). O poeta então afirma que as águas desse mar 'ninguém acaba não'.

Compreender as entrelinhas desta estrutura narrativa escrita é averiguar os núcleos de sentidos que estão sendo transmitidos. O contexto representa elementos significativos para a região, como o pé de juazeiro, o sabiá, os rios etc., provocando no leitor as características de uma região.

\subsection{Cariri - o hino}

A poesia Cariri - $O$ hino expressa reverência ao local, como mostra o Mapa Conceitual 4. Os trechos do hino: 'sol que ilumina o Cariri, as cachoeiras no canto das águas relatam a sonoridade das águas entre as pedras'.

O sol brilhou no Cariri/E as cachoeiras no canto das águas/A me encantar/O canto que encanto o sopé/Canta chapada, canta o sol, Canta Cariri. (JAMACARU, 1986).

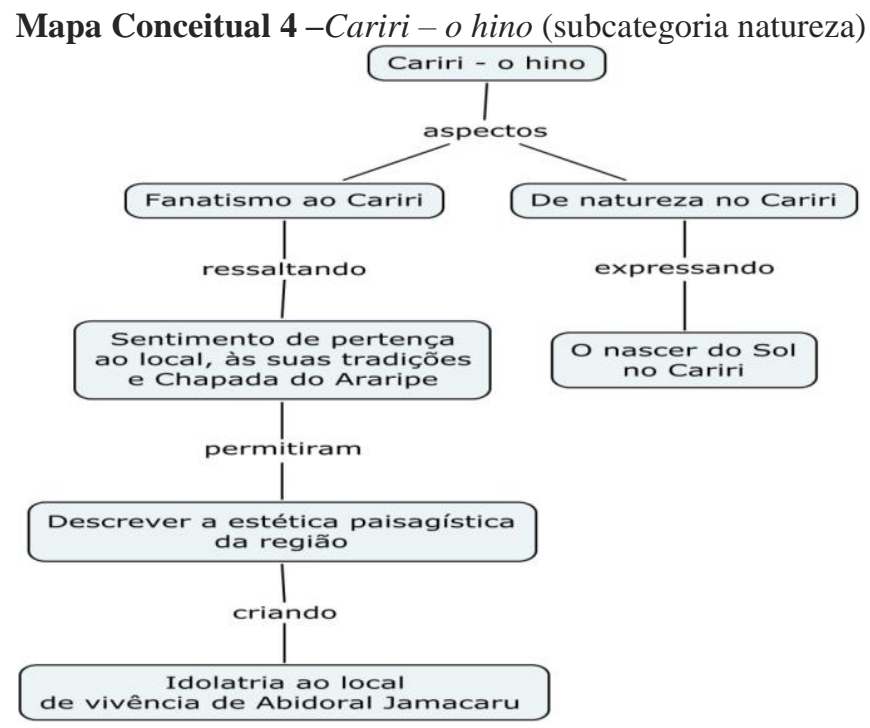

Fonte: Elaborado pelos autores. 
Adiante há um trecho que diz: 'pois tenho aconchego dos teus braços', no qual é perceptível o sentimento de pertença à região do Cariri, as suas tradições, a Chapada do Araripe, o que novamente relembra, ou seja, descreve a estética paisagística dos lugares em que presenciou desde a sua infância: "Pois tenho o aconchego dos teus braços/Te amo chapada, te amo Cariri. (JAMACARU, 1986).

Ao demonstrar o seu amor 'te amo chapada, te amo Cariri', há a compreensão da relação de pertencimento e identificação com as características da região do Cariri, interceptado por diversos personagens históricos que compõem a cultura regional como, por exemplo, Patativa do Assaré e Bárbara de Alencar, já referida inicialmente.

O poema demonstra singela idolatria à região que foi - e é - o local de vivência de Abidoral Jamacaru, mesmo não sendo escrita pelo poeta, percebe-se inserido na obra dele, como representativo dos aspectos paisagísticos do Cariri, nesse caso, presume-se a inserção desse discurso escrito na obra de Abidoral Jamacaru.

\subsection{Vou no vento}

Em parceria com a professora da Universidade Regional do Cariri (URCA), Claudia Rejane e Abidoral Jamacaru apresentam traços das suas idas à Chapada do Araripe, na qual (Abidoral Jamacaru) obteve conhecimento vasto sobre os animais e plantas (Mapa Conceitual 5): "Ó mainha, eu vou no vento/Pra Chapada do Araripe/Vou fazer uma cantiga/Vou passear por ali." (JAMACARU; REJANE, 1986). Já de acordo com a segunda estrofe: "Trago a sede de esperança/Um baú pra colher paz/(...) O teu chão será meu pai/E a floresta minha mãe.” (JAMACARU; REJANE, 1986).

Demonstra a esperança de um povo em busca de paz. No verso: 'o teu chão será meu pai e a floresta minha mãe', o chão, no qual pisa, traz analogia com o que o "sustenta", o põe de pé, o ajuda. Já a floresta é a representação materna, de acolhimento, etc.

Nesse discurso, há a memória da infância, de sair para andar entre a mata da Chapada do Araripe, um indivíduo em busca do que se apresenta como 
natural. $\mathrm{Na}$ entrevista cedida para esta pesquisa, Abidoral Jamacaru afirma que as experiências de vida, seu contato com a Chapada do Araripe e o período de contracultura no Cariri em 1970 foram fundamentais para compor a suas obras. Segundo o poeta, em entrevista cedia ao pesquisador Alves (2018):

Todas as músicas, eu não fiz pensando em fazer uma música porque essa música seria sucesso, ou porque essa música estaria em evidência no que está em modismo nos veículos de comunicação. Não! Era realmente uma coisa que estava dentro e mim e que eu tinha necessidade de exteriorizar né? Entendeu? Então elas... São coisas que fazem parte da vida da gente, da coisa toda. E teve essa coisa de nascer de uma forma espontânea mesmo. [...] Você exterioriza aquilo que você vivenciou né? Entendeu? (ALVES, 2018, p. 74-75).

Mapa Conceitual 5 - Vou no vento (subcategoria natureza)

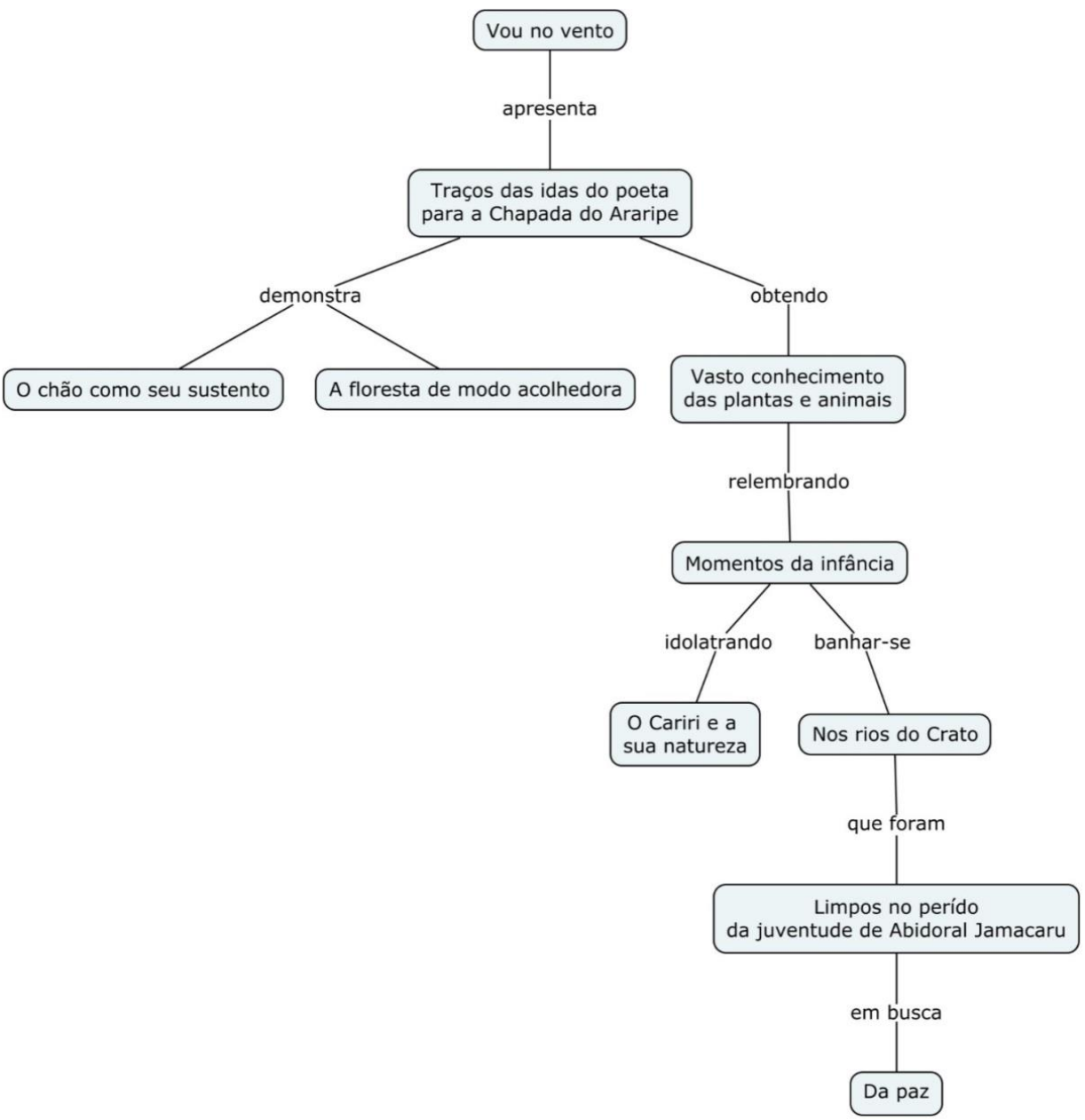

Fonte: Elaborado pelos autores. 
Novamente, nesse poema, é característica a presença dos aspectos naturais do Cariri, provindos pela memória de infância do poeta e representados na sua escrita narrativa. Dessa forma, é apresentado um cenário de idolatria ao local, imerso de memória construída de modo empírico, de vivência, de contato com a terra.

\section{Considerações finais}

Considera-se que as estéticas paisagísticas da cidade de Crato, sobretudo o período da década de 70, foram de fundamental importância para a representação dos aspectos sociais vigentes da época representada na obra de Abidoral Jamacaru. No que concerne à memória, foi compreendida a poesia de Abidoral Jamacaru enquanto registro de memória (materializada em CDs), já no que tange ao conjunto de sua obra, nem todas as poesias trabalhavam com temáticas regionais (como estabelecidas neste trabalho em seções anteriores) visto que o poeta, diante das suas concepções de mundo, representa de modo escrito, outras temáticas. O presente estudo se pauta na Região do Cariri Cearense, assim, o poeta representa o Cariri em cinco poesias categorizadas e analisadas, sendo uma com vertente política, através da ativista Bárbara de Alencar, e as outras quatro com temas da natureza, abrangendo a flora e a fauna. A ótica de análise da Ciência da Informação permitiu trabalhar de modo teórico e metodológico no que tange à memória e poesia, mas, sobretudo, na metodologia e, consequentemente, na operacionalização dos dados.

\section{Financiamento}

O presente trabalho foi realizado com apoio da Coordenação de Aperfeiçoamento de Pessoal de Nível Superior - Brasil (CAPES) - Código de Financiamento 001. 


\section{Referências}

BERNARDES, D. Bárbara de Alencar [Entrevista cedida a] Vera Barroso e Ancelmo Goes. Rio de Janeiro: Tv Brasil, 2010. Vídeo (30 min), son., color.

ALVES, E. N. P. Memória e Poesia: uma análise dos escritos poéticos de Abidoral Jamacaru. 2015. Trabalho de Conclusão de Curso (Bacharelado em Biblioteconomia) - Curso de Biblioteconomia, Universidade Federal do Cariri, Juazeiro do Norte, 2015.

ALVES, E. N. P.. Abidoral Jamacaru: a poesia como elemento de memória na região do cariri cearense. 2018. Dissertação (Mestrado em Ciência da Informação) - Curso de Ciência da Informação, Universidade Federal de Pernambuco, Recife, 2018.

ARAÚJO, A. Bárbara de Alencar. 3 ed. rev. e atualizada. Fortaleza: Edições Demócrito Rocha, 2002. 64p.

AZEVEDO NETTO, C. X. de. Informação e memória: as representações através da cultura material. Revista História em Reflexão, Dourados, v. 1, n. 2, p. 120, 2004. Trabalho apresentado no $5^{\circ}$ Encontro Nordestino de História, 2004, [s.l.].

BÁRBARA. Intérprete: Abidoral Jamacaru. Compositores: Abidoral Jamacaru e Pachelly Jamacaru. In: JAMACARU, Abidoral. Bárbara. [Compositor e intérprete]: Abidoral Jamacaru. [S. l.: s. n.], 2008.

BARDIN, L. Análise de conteúdo. Lisboa: Edições 70, 1997.

CONSOLANÇA. Intérprete: Abidoral Jamacaru. Compositores: Abidoral Jamacaru e Claudia Rejane. In: JAMACARU, Abidoral. Peixe. [Compositor e intérprete]: Abidoral Jamacaru. [S. l.: s. n.], 1998.

DETIENNE, M. Mestres da Verdade na Grécia Arcaica. Rio de Janeiro: Jorge Zahar, 1988.

DIAS, C. R. Da flor da terra aos guerreiros cariris: representações e identidades do Cariri cearense (1855-1980). 2014. Dissertação (Mestrado em História) - Faculdade de Programa de Pós-graduação em História, Universidade Federal de Campina Grande, Campina Grande, 2014.

ESALQ. Juazeiro. Piracicaba: USP, [2010?].

FRANCO, M. L. Puglisi. Barbosa. Análise de conteúdo. 2. ed. Brasília: Liber Livro, 2005.

HALL, S. A identidade cultural na pós-modernidade. Rio de Janeiro: Dp\&a, 2011. 
LE GOFF, J. História e memória. Campinas: Editora da Unicamp, 1990.

LIMA, G. Â. B. de O. Mapa conceitual como ferramenta para organização do conhecimento em sistema de hipertextos e seus aspectos cognitivos. Perspectivas em ciência da informação, Belo Horizonte, v. 9, n. 2, p. 134-145, 2004.

LOPES, S. R. A poesia, memória excessiva. Revista da Faculdade de Ciências Sociais e Humanas, Lisboa, n. 9, p. 155-161, 1996.

LUNA, C. Bárbara de Alencar, de inimiga do rei a heroína nacional: percursos da imaginação histórica e modelos de representação literária. Mulheres e Literatura, [s. l.] , v. 15, 2015.

MARQUES, R. Contracultura, tradição e oralidade: (re) inventando o Sertão Nordestino em tempos velozes. Trajetos, Fortaleza, v. 3, n. 6, p. 201-216, 2005.

MARQUES, R. Seja moderno, seja marginal: engenhos e artimanhas da contracultura no Cariri. Sociedade e Cultura, Goiás, v. 11, n. 2, p. 191-198, 2008.

MCGARRY, K. O contexto dinâmico da informação. Brasília: Briquet de Lemos, 1999.

MENESES, S.; CORDEIRO, P. Narradores do Cariri: olhares contemporâneos e as reinvenções de um lugar incomum. Caderno de Cultura e Ciência, Crato, v. 13, n. 1, p. 77-84, 2014.

NORA, P. Entre memória e história: a problemática dos lugares. Projeto História, São Paulo, v. 10, n. 1, p. 7-28, 1993.

OLIVEIRA, E. B. de; RODRIGUES, G. M. O conceito de memória na Ciência da Informação: análise das teses e dissertações dos programas de pós-graduação no brasil. Liinc em Revista, Rio de Janeiro, v. 1, n. 7, p. 311-328, 2011.

PASCOAL, D. Execução de Pe. Mororó ocorreu há 183 anos. Diário do Nordeste, Fortaleza, 3 maio 2008.

PRA ninar o Cariri. Intérprete: Abidoral Jamacaru. Compositor: Abidoral Jamacaru. In: JAMACARU, Abidoral. Avallon. [Compositor e intérprete]: Abidoral Jamacaru. [S. l.: s. n.], 1986.

RODRIGUES, A. D. Tradição e modernidade. Revista da Faculdade de Ciências Sociais e Humana, Lisboa, v. 9, n. 1, p. 301-308, 1996.

SANTOS, E. Rio Salgado em discussão. Diário do Nordeste, Fortaleza, 19 maio 2008. 
SILVA, J. L. C. A teoria matemática da comunicação na ciência da informação: propondo uma nova relação entre sujeitos da informação. Pesquisa Brasileira em Ciência da Informação e Biblioteconomia, João Pessoa, v. 11, n. 1, p. 203$217,2016$.

SOUSA, K. S. de. Bárbara de Alencar: relações de gênero e poder no cariri cearense. 2015. 115 f. Dissertação (Mestrado) - Curso de Políticas Públicas e Sociedade, Universidade Federal do Ceará, Fortaleza, 2015. Disponível em: http://www.uece.br/politicasuece/dmdocuments/Disserta\%C3\%A7\%C3\%A3o_ Kelyane.pdf. Acesso em: 27 jul. 2020.

SMOLKA, A. L. B. A memória em questão: uma perspectiva histórico-cultural. Educação e sociedade, Campinas, v. 71, n. 71, p. 166-193, 2000.

VAINSENCHER, S. A. Bárbara Pereira de Alencar. [S. l.]: Portal CEN - Ca estamos nos, [2010?].

VIANA, J. I. B. O Instituto Cultural do Cariri e o centenário do Crato [manuscrito]: memória, escrita da história e representações da cidade. 2011. Dissertação (Mestrado em História Social) - Curso de Programa de Pósgraduação em História, Universidade Federal do Ceará, Fortaleza, 2011.

VICELMO, A. Crato lidera na safra do pequi. Diário do Nordeste, Fortaleza, nov. 2007.

VOU no vento. Intérprete: Abidoral Jamacaru. Compositor: Abidoral Jamacaru. In: JAMACARU, Abidoral. Avallon. [Compositor e intérprete]: Abidoral Jamacaru. [S. l.: s. n.], 1986.

\title{
The poetic of Abidoral Jamacaru as a record of memory and representation of knowledge
}

\begin{abstract}
It identifies the poetry of Abidoral Jamacaru as a memory record of the region to the south of the state of Ceará, Cariri. It contextualizes the poet in the decade of 'modern marginals', that is, in the counterculture movement in the 1970 years, in which the artist begins to have visibility and to recognize himself as a subject who influenced in a given period. Conceptualizes memory under the bias of the information science, dialoguing with the historical conceptions of poetry. As for the methodological procedure, the research is used in the content analysis, as well as the thematic analysis in the operationalization of data. The conceptual maps were inserted as graphic types of representation of knowledge, expanding the ways of visualizing the poetry of Abidoral Jamacaru. It concludes that the landscape aesthetics of the city of Crato and the movements of counterculture in the Cariri influenced the composition of poetic writings of
\end{abstract}




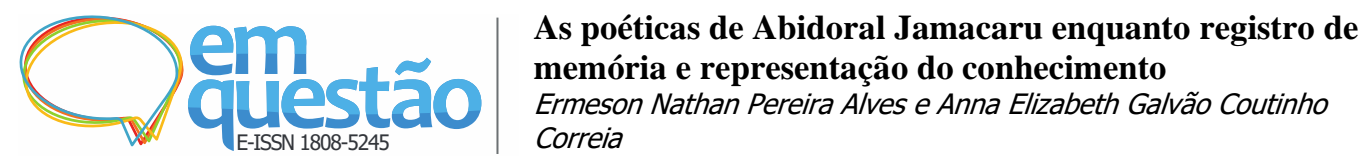

the author, composing it the individual memory that dialogues with the local memory of the region, creating an identity in their works.

Keywords: Abidoral Jamacaru. Memory register. Counterculture Representation of knowledge. Information Science.

Recebido: $26 / 02 / 2020$

Aceito: 20/04/2020

Concepção e elaboração do estudo: Ermeson Nathan Pereira Alves Coleta de dados: Ermeson Nathan Pereira Alves

Análise e interpretação de dados: Ermeson Nathan Pereira Alves, Anna

Elizabeth Galvão Coutinho Correia

Redação: Ermeson Nathan Pereira Alves, Anna Elizabeth Galvão Coutinho

Correia

Revisão crítica do manuscrito: Ermeson Nathan Pereira Alves, Anna Elizabeth Galvão Coutinho Correia

\section{Como citar}

ALVES, Ermeson Nathan Pereira; CORREIA, Anna Elizabeth Galvão

Coutinho. As poéticas de Abidoral Jamacaru enquanto registro de memória e representação do conhecimento. Em Questão, Porto Alegre, v. 27, n. 1, p. 5990, 2021. Doi: http://dx.doi.org/10.19132/1808-5245271.59-90

\footnotetext{
${ }^{1}$ MARTINS, José Edson. O Cordel, o homossexual e o poeta "maudito": novelo de discursos no folheto de Salete Maria e Fanka Santos. Estudos de Literatura Brasileira Contemporânea, Brasília, n. 22, p. 125-136, 2003. Apud Marques (2005).
} 